\title{
ESTUDO COMPARATIVO DO COEFICIENTE DE DIFUSÃO, PERMEABILIDADE AO VAPOR D'ÁGUA, E TEOR DE UMIDADE DE FILMES DE QUITOSANA COM ADIÇÃO DE CORANTES.
}

\author{
R. C. FONSECA ${ }^{1}$, A. B. dos REIS ${ }^{1}$ \\ ${ }^{1}$ Universidade Federal dos Vales do Jequitinhonha e Mucuri, Instituto de Ciência e \\ Tecnologia \\ Email para contato: roberta_cardosof@yahoo.com.br
}

RESUMO - A utilização de corantes é pratica comum na indústria química, já que a cor e a aparência têm um papel importante na aceitação dos produtos pelo consumidor. Em contrapartida, de grande interesse existe o mercado de substituição de polímeros sintéticos por polímeros naturais dando ênfase aos que podem ser utilizados como veículo para adição de outros produtos, como os corantes, Urucum, Antocianina e Clorofila, com várias aplicações, dentre as quais sua utilização como indicadores. O presente trabalho teve como objetivo um estudo preliminar do coeficiente de difusão de filmes de quitosana com adição dos corantes citados, avaliando as possibilidades de utilização dos corantes como indicadores. Para tanto, foram realizadas análises preliminares como: análise visual, flexibilidade, espessura, Permeabilidade ao Vapor D'água (PVA) e Coeficiente de Difusão. Donde se pode observar que a proximidade das características dos filmes de quitosana com adição do corante Clorofila, com os filmes de quitosana sem adição de corante, podendo, portanto, serem substituídos por tal. 


\section{1 - INTRODUÇÃO}

No cenário atual, os biopolímeros têm substituído os compostos sintéticos como resultado da exigência do mercado por tecnologias sustentáveis. O desenvolvimento sustentável procura balancear o respeito ao meio ambiente e o desenvolvimento econômico. Os biofilmes são produzidos a partir de compostos naturais, característica favorável a ações de degradabilidade, dentre esses compostos podemos citar a quitosana. A quitosana veem sendo largamente utilizada na indústria de embalagem e em diversas outras áreas. O extenso uso da quitosana está relacionado com sua biodegradabilidade e sua ação antiumectante e antioxidante. (FARIAS, 2012)

A quitosana é um copolímero de (1-4)-L-amino-2-deoxi- $\beta$-D-glucona (Dglucosamina), forma desacetilada da quitina, que é um dos mais extensos polissacarídeos em biomassa, podendo ser obtida a partir de carapaças de crustáceos, como camarão, caranguejo e lagosta. (LARANJEIRA; FÁVERE, 2009)

Além das vantagens sustentáveis, a quitosana chama a atenção devido à sua capacidade de formar películas. A partir de alguns estudos, foi comprovado que a as películas de quitosana são excelentes barreiras ao $\mathrm{O}_{2}$, quando comparadas com polímeros comerciais. A importância dessa propriedade dá se devido ao fato do $\mathrm{O}_{2}$ ser um grande percursor da diminuição de vida útil de alimentos acondicionados, pelas reações oxidativas causadas pela influência do transporte e armazenagem. (BUTLERET al., 1996)

No setor de embalagens, por exemplo, a quitosana vem sendo utilizada como embalagens ativas e inteligentes, aproveitando-se da sua característica que permite ser utilizada como veículo para adição de outros aditivos, como é o caso dos indicadores de umidade, deterioração, $\mathrm{pH}, \mathrm{CO}_{2}, \mathrm{O}_{2}$ e outros compostos indesejáveis na armazenagem de produtos diversos. (ARAÚJO, 2004)

O uso de indicadores que já vem sendo utilizado com frequência pode ser inserido na matriz polimérica de filmes de quitosana como, por exemplo, a adição de corantes. Dentro da possibilidade de uso de corantes podemos citar as antocianicas, clorofila, betacarotenos, urucum, etc. Além de possuírem características antioxidantes, antiumectantes, são de baixo custo.

O presente trabalho teve como objetivo o estudo do efeito da adição dos corantes, Urucum, Clorofila e Antocianina, na elaboração da matriz polimérica de filmes de quitosana na concentração $4 \%$ em massa. 


\section{2 - MATERIAIS}

Quitosana (Polymar), ácido acético (Synth, Brasil), Corantes Urucum, Clorofila, Antocianina (CHR HANSEN) e Sílica.

\section{3 - METODOLOGIA}

\section{1 - PRODUÇÃO DE FILMES}

Em laboratório foi preparada a solução filmogênica de quitosana com adição de corante de urucum, clorofila e antocianina, e solução filmogênica de quitosana.

\section{2 - ANÁLISE VISUAL}

A análise visual foi realizada para efeito comparativo entre os filmes de quitosana com e sem adição de corantes donde pode-se concluir que os filmes quitosana com adição dos corantes obtiveram coloração, e maior flexibilidade do que os filmes sem adição de corantes.

\section{3 - ESPESSURA}

Após a retirada dos filmes e a partir da analise visual, observou- se que os filmes de quitosana com adição do corante de antocianina possuíam maior espessura, porém, apresentaram comportamento quebradiço.

\section{4 - PERMEABILIDADE AO VAPOR D’ÁGUA}

A permeabilidade ao vapor d'água (PVA) foi determinada nos filmes: padrão (filme contendo somente quitosana), filme-urucum (filme-padrão com adição do corante urucum), filme-clorofila (filme-padrão com adição do corante clorofila), filmeantocianina (filme-padrão com adição do corante antocianina).

A permeabilidade ao vapor d'água (PVA) foi obtida através da equação:

$$
P V A=\frac{\Delta m(g) * \text { Espessura }_{\text {média }}(m m)}{\text { Área do Filme }\left(m^{2}\right) * \Delta t(h) * \Delta P(K p a)}
$$

\section{4 - RESULTADOS E DISCUSSÃO}


Os filmes obtidos a partir de quitosana sem aditivos (filme padrão) apresentaram se transparentes cor levemente amarelada, compactos (com ausência de poros ou falhas), flexíveis e de difícil rompimento. A partir desta matriz filmogênica foram adicionados corante natural de urucum, clorofila e antocianina formando filmes ativos. Os mesmos apresentaram se de cor laranjada, verde e roxa, respectivamente, compactos, flexíveis e resistentes.

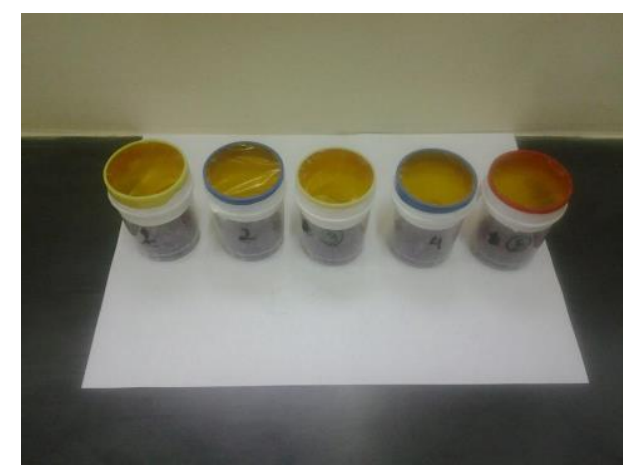

Figura 2 - Amostras de filmes de quitosana com adição de corante de urucum.

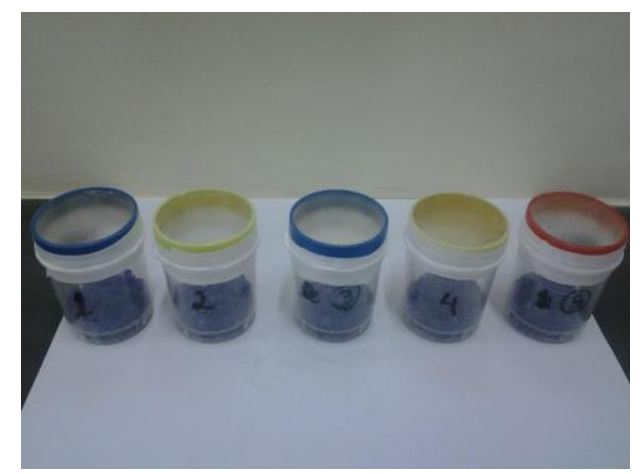

Figura 1 - Amostras com filmes de quitosana sem adição de corantes.

A partir dos dados adquiridos foi feito o estudo comparativo dos filmes de quitosana com adição dos corantes citados, com os filmes de quitosana sem adição de corante.

Tabela 1 - Analises de PVA de amostras de filmes de quitosana.

\begin{tabular}{c|cccccc}
\hline Amostras & $\Delta \mathbf{m}(\mathbf{g})$ & $\begin{array}{c}\text { Espessura } \\
\mathbf{( m m})\end{array}$ & $\begin{array}{c}\text { Área do } \\
\left(\mathbf{m}^{2}\right)\end{array}$ & $\begin{array}{c}\text { Tempo }(\mathbf{h}) \\
\text { Ailme }\end{array}$ & $\Delta \mathbf{P}(\mathbf{K P a})$ & PVA \\
\hline $\mathbf{A 1}$ & 0,8130 & 0,1862 & 0,00159 & 120 & 2,3 & 0,3450 \\
$\mathbf{A 2}$ & 0,7842 & 0,1924 & 0,00159 & 120 & 2,3 & 0,3438 \\
$\mathbf{A 3}$ & 0,7327 & 0,1694 & 0,00159 & 120 & 2,3 & 0,2828 \\
$\mathbf{A 4}$ & 0,6924 & 0,1632 & 0,00159 & 120 & 2,3 & 0,2575 \\
$\mathbf{A 5}$ & 0,7138 & 0,1728 & 0,00159 & 120 & 2,3 & 0,2811 \\
$\mathbf{A 6}$ & 0,8317 & 0,2058 & 0,00159 & 120 & 2,3 & 0,3900 \\
$\mathbf{A 7}$ & 0,7812 & 0,1832 & 0,00159 & 120 & 2,3 & 0,3261 \\
$\mathbf{A 8}$ & 0,7878 & 0,1920 & 0,00159 & 120 & 2,3 & 0,3447 \\
$\mathbf{A 9}$ & 0,7765 & 0,1986 & 0,00159 & 120 & 2,3 & 0,3514 \\
$\mathbf{A 1 0}$ & 0,6495 & 0,1528 & 0,00159 & 120 & 2,3 & 0,2261 \\
\hline
\end{tabular}


Tabela 2 - Analises de PVA de amostras de filmes de quitosana com adição de corante de urucum.

\begin{tabular}{|c|c|c|c|c|c|c|}
\hline Amostras & $\Delta \mathbf{m}(\mathbf{g})$ & $\begin{array}{c}\text { Espessura } \\
\text { Média } \\
(\mathbf{m m})\end{array}$ & $\begin{array}{c}\text { Área do } \\
\text { Filme } \\
\left(\mathbf{m}^{2}\right)\end{array}$ & Tempo (h) & $\Delta \mathbf{P}(\mathbf{K P a})$ & PVA \\
\hline A1 & 1,0665 & 0,2670 & 0,00159 & 120 & 2,3 & 0,6489 \\
\hline $\mathbf{A} 2$ & 1,1564 & 0,2402 & 0,00159 & 120 & 2,3 & 0,6329 \\
\hline A3 & 1,1830 & 0,2622 & 0,00159 & 120 & 2,3 & 0,7068 \\
\hline A4 & 1,0724 & 0,2142 & 0,00159 & 120 & 2,3 & 0,5234 \\
\hline A5 & 1,0990 & 0,3166 & 0,00159 & 120 & 2,3 & 0,7928 \\
\hline A6 & 1,1819 & 0,2216 & 0,00159 & 120 & 2,3 & 0,5968 \\
\hline A7 & 1,1378 & 0,2434 & 0,00159 & 120 & 2,3 & 0,6310 \\
\hline A8 & 1,1537 & 0,2424 & 0,00159 & 120 & 2,3 & 0,6373 \\
\hline A9 & 1,1290 & 0,2388 & 0,00159 & 120 & 2,3 & 0,6144 \\
\hline A10 & 1,0912 & 0,2582 & 0,00159 & 120 & 2,3 & 0,6420 \\
\hline
\end{tabular}

Tabela 3 - Analises de PVA de amostras de filmes de quitosana com adição de corante de Clorofila.

\begin{tabular}{c|cccccc}
\hline \multirow{2}{*}{ Amostras } & $\Delta \mathbf{m}(\mathbf{g})$ & $\begin{array}{c}\text { Espessura } \\
\text { Média } \\
(\mathbf{m m})\end{array}$ & $\begin{array}{c}\text { Área do } \\
\text { Filme }\left(\mathbf{m}^{2}\right)\end{array}$ & Tempo (h) & $\Delta \mathbf{P}(\mathbf{K P a})$ & PVA \\
& & 0,2508 & 0,00159 & 120 & 2,3 & 0,5615 \\
$\mathbf{A 1}$ & 0,9825 & 0,1862 & 0,00159 & 120 & 2,3 & 0,3542 \\
$\mathbf{A 2}$ & 0,8347 & 0,2202 & 0,00159 & 120 & 2,3 & 0,4311 \\
$\mathbf{A 3}$ & 0,8591 & 0,1650 & 0,00159 & 120 & 2,3 & 0,3226 \\
$\mathbf{A 4}$ & 0,8580 & 0,2360 & 0,00159 & 120 & 2,3 & 0,5276 \\
$\mathbf{A 5}$ & 0,9811 & 0,2150 & 0,00159 & 120 & 2,3 & 0,4466 \\
$\mathbf{A 6}$ & 0,9115 & 0,1926 & 0,00159 & 120 & 2,3 & 0,3468 \\
$\mathbf{A 7}$ & 0,7902 & 0,2090 & 0,00159 & 120 & 2,3 & 0,4706 \\
$\mathbf{A 8}$ & 0,9880 & 0,1928 & 0,00159 & 120 & 2,3 & 0,3700 \\
$\mathbf{A 9}$ & 0,8421 & 0,390 & & \\
$\mathbf{A 1 0}$ & 0,8672 & 0,1888 & 0,00159 & 120 & 2,3 & 0,3731
\end{tabular}


Tabela 4 - Analises de PVA de amostras de filmes de quitosana com adição de corante de Antocianina.

\begin{tabular}{|c|c|c|c|c|c|c|}
\hline Amostras & $\Delta \mathbf{m}(\mathrm{g})$ & $\begin{array}{c}\text { Espessura } \\
\text { Média } \\
(\mathbf{m m})\end{array}$ & $\begin{array}{c}\text { Área do } \\
\text { Filme } \\
\left(\mathbf{m}^{2}\right)\end{array}$ & Tempo (h) & $\Delta \mathbf{P}(\mathbf{K P a})$ & PVA \\
\hline A1 & 0,9628 & 0,2618 & 0,00159 & 120 & 2,3 & 0,5744 \\
\hline $\mathbf{A 2}$ & 1,1428 & 0,2708 & 0,00159 & 120 & 2,3 & 0,7052 \\
\hline $\mathbf{A 3}$ & 1,1509 & 0,2820 & 0,00159 & 120 & 2,3 & 0,7396 \\
\hline A4 & 0,8903 & 0,2072 & 0,00159 & 120 & 2,3 & 0,4203 \\
\hline A5 & 1,1904 & 0,3082 & 0,00159 & 120 & 2,3 & 0,8360 \\
\hline A6 & 0,9464 & 0,2434 & 0,00159 & 120 & 2,3 & 0,5249 \\
\hline A7 & 1,0576 & 0,2662 & 0,00159 & 120 & 2,3 & 0,6415 \\
\hline A8 & 1,0744 & 0,2416 & 0,00159 & 120 & 2,3 & 0,5915 \\
\hline A9 & 0,9768 & 0,2452 & 0,00159 & 120 & 2,3 & 0,5458 \\
\hline A10 & 0,9267 & 0,2310 & 0,00159 & 120 & 2,3 & 0,4878 \\
\hline
\end{tabular}

As tabelas acima mostram a média dos resultados obtidos durante os experimentos. A partir das mesmas é possível comparar a Permeabilidade de Vapor D’Água, Coeficiente de Difusão e Teor de Umidade das amostras.

Tabela 5 - Comparativo entre os Coeficientes de Difusão, PVA e Teor de Umidade entre as Amostras.

\begin{tabular}{|c|c|c|c|}
\hline \multicolumn{4}{|c|}{$\begin{array}{c}\text { Comparativo entre os Coeficientes de Difusão, PVA e } \\
\text { Teor de Umidade entre as Amostras. }\end{array}$} \\
\hline & $\begin{array}{c}\text { Coeficiente de } \\
\text { Difusão }\end{array}$ & PVA & $\begin{array}{l}\text { Teor De } \\
\text { Umidade }\end{array}$ \\
\hline $\mathbf{Q}$ & $-4,0669 \mathrm{E}-06$ & 0,2828 & 2,083831 \\
\hline $\mathbf{Q U}$ & $1,2826 \mathrm{E}-04$ & 0,6329 & 1,769755 \\
\hline QC & $6,2099 \mathrm{E}-05$ & 0,4311 & $-0,25778$ \\
\hline QA & $6,1078 \mathrm{E}-04$ & 0,5311 & 0,403768 \\
\hline
\end{tabular}

Legenda: Q - Quitosana;

QU - Filmes de Quitosana com Adição de corante Urucum;

QC - Filmes de Quitosana com Adição do corante Clorofila;

QA - Filmes de Quitosana com Adição do corante Antocianina. 


\section{5 - CONCLUSÕES}

A partir das análises, pode- se concluir que, as amostras de filmes de quitosana com adição do corante Clorofila, apresentaram coeficiente de difusão e Permeabilidade ao Vapor D’Água aproximado aos respectivos, da solução- padrão. Assim sendo, tais amostras, se mostraram eficientes quanto à retenção de vapor d'água, podendo ser utilizadas em materiais, para conservação de propriedades.

As amostras de filmes de quitosana adicionados do corante Antocianina, embora tenha apresentado coeficiente de difusão e Permeabilidade ao Vapor D’Água, menores que os filmes de quitosana adicionados do corante Urucum, visualmente demonstraram propriedades mecânicas frágeis, num comportamento quebradiço.

Partindo do pressuposto de que o presente trabalho visou apenas o intuito de relacionar os filmes de quitosana com os filmes de quitosana adicionado aos corantes, Urucum, Clorofila e Antocianina, donde pode- se concluir que a aplicação dos filmes de quitosana com adição dos corantes, Urucum, Clorofila e Antocianina, deve variar de acordo com a necessidade da aplicação, exigindo, portanto, estudos mais aprofundados.

\section{6 - REFERÊNCIAS BIBLIOGRÁFICAS}

ANAIS DO VIII SEMINÁRIO DE PESQUISA EM CIÊNCIAS HUMANAS, 2010, Londrina. A INDÚSTRIA QUÍMICA NO BRASIL. Londrina: Eduel, 2010. 9 p.

ARAÚJO, Júlio. Química De Alimentos: Teoria E Prática. 3ed. Viçosa: Ed. UFV, 2004.

CAMPAGNA-FILHO, S. P.; Signini, R.; Polímeros: Ciên. e Tecnol. 2001, 11, 169.

CASALES, Maria Rosa; CAPACCIONI, Maria Eugenia; YEANNES, Maria Isabel. Obtenção dos tempos de equilíbrio e coeficientes de difusão de ácido e de sal para desenhar o processo de marinado de filés de Engraulis anchoita. Ciência Tecnologia de Alimentos, Campinas, v. 29, n. 4, p.933-937, dez. 2009.

FARIAS, Mônica Guimarães, et al,. O Efeito Da Permeabilidade Ao Vapor De Água, Atividade De Água, Molhabilidade E Solubilidade Em Água Em Filmes De Amido E Polpa De Acerola. Embrapa Agroindústria Tropical,: VI Workshop da Rede de Nanotecnologia Aplicada ao Agronegócio, Fortaleza, p.135-137, abr. 2012.

LARANJEIRA, Mauro C. M.; FÁVERE, Valfredo T. de. Quitosana: biopolímero funcional com potencial industrial biomédico. Química Nova, Florianópolis, v. 32, n. 3, p.672-678, abr. 2009. 